\title{
An Overview of Solid Waste Resource Recovery Efforts in Lagos
}

\author{
Folahan Anthony Adenaike ${ }^{1,2, \dagger}$, Abayomi Josiah Omotosho ${ }^{3, \dagger}$ \\ ${ }^{1}$ Department of Architectural Technology, School of Environmental Studies, Lagos State Polytechnic, Ikorodu, Nigeria \\ ${ }^{2}$ Department of Architecture, College of Science and Technology, Covenant University, Ota, Nigeria \\ ${ }^{3}$ Department of Architectural Technology, Lagos State Polytechnic, Ikorodu, Nigeria
}

Email address:

folahanadenaike@gmail.com (F. A. Adenaike), yomitosho@yahoo.com (A. J. Omotosho)

$\dagger$ Folahan Anthony Adenaike and Abayomi Josiah Omotosho are co-first authors.

\section{To cite this article:}

Folahan Anthony Adenaike, Abayomi Josiah Omotosho. An Overview of Solid Waste Resource Recovery Efforts in Lagos. American Journal of Environmental and Resource Economics. Vol. 5, No. 3, 2020, pp. 44-49. doi: 10.11648/j.ajere.20200503.11

Received: June 30, 2020; Accepted: July 14, 2020; Published: July 28, 2020

\begin{abstract}
Resource recovery from solid waste is of immense benefit for any society in terms of sustainability and economic diversification. It directly addresses the problem of waste overload as well as resource scarcity. This study assesses the efforts made by Lagos State of Nigeria to recover resources from solid wastes since 2007. It highlights the different programs and policies of the state in resource recovery and carried out a questionnaire survey of the citizens' awareness and response to the government efforts. While the residents are conscious of the government position and are ready to get involved in its actualization, there is however, a very low level of implementation especially in the infrastructure. The study concludes that to improve the Lagos State resource recovery model, there is a need to approach it more globally, starting with the redirection of the polity towards a circular economy and encouraging inclusiveness especially with the private sector.
\end{abstract}

Keywords: Municipal Solid Waste, Waste Management, Resource Recovery, Circular Economy

\section{Introduction}

The percentage of Nigeria's population living in cities and urban areas has been increasing exponentially over the years [1]. This continuous growth contributes to enormous generation of solid and liquid wastes. Lagos is Africa's most populated city [2]. In 2014, 13,000 tonnes of waste were generated daily by 20million residents of Lagos [3]. The current generation by extrapolation should be in excess of 20,000 tons per day [4]. The current practice for management of general waste is to take them to dumpsites where scavengers pick items that are recyclable for the factories in the area and sell to vendors who go round the dumpsites to pick the items. The items usually recovered by the scavengers are mostly metals and plastics. The only glass materials that are recovered from the dump sites are whole bottles. The rest of the solid wastes which comprise mostly biodegradable materials and other objects that escape the scrutiny of the dump site scavengers are left to degenerate into the dumpsites as land fill. Other classes of solid wastes like medical wastes, e-wastes and hazardous chemicals are recovered from their points of generation and processed specially either for recycling or disposal. There are specified guidelines by the Lagos State Environmental Protection Agency (LASEPA) for each of the facilities that generate such wastes on how they must be processed. Bio wastes from agricultural products processing like those found in markets, abattoirs and farms are usually recycled within the agricultural sector of the economy and manufacturing facilities. The scope of this study precludes these special classes of waste since adequate guidelines and monitoring sufficiently guide the recovery and processing of such wastes. The bulk of the solid waste generated in Lagos is the municipal solid waste from residential and commercial locations in the state.

The first major attempt at resource recovery from solid waste in Lagos was initiated in 1981. The government built 5 incinerating plants around the state. The target was to build one incinerating plant in each local government area [5]. The program never took off due to lack of logistic analysis and 
the unwillingness mostly on the part of the municipal authorities to deviate from the existing processes and embrace the new arrangement. The wastes were supposed to be deposited in sorting centers close to the incinerating plants for processing. Once sorting is carried out, the reusable contents will be removed by the consumers of the items. The rest can then be incinerated. The incinerators constructed were never put to use. In the year 2000, Lagos state government as part of their millennium initiatives called for proposals for "waste to wealth" program under the Ministry of Environment and Physical Planning. The outcome of the exercise has not been made public. There has been more effort in managing the waste disposal than recovery. LASEPA and the Federal Ministry of Environment in Lagos show a strong presence in manufacturing facilities to ensure that they meet up with international standards of waste disposal for their solid wastes and effluents. The management of wastes at the landfill sites is yet to witness appreciable changes. The modern approach to waste management is to reduce, recover, recycle and reuse (RRRR). The three Rs (Recover, recycle and reuse) have changed to four Rs. Of importance in this study is to recover and make available for either recycling or reusing. The practice of treating waste materials as a resource is becoming popular especially in metropolitan areas where there is limited land for new landfills. There is increasing awareness that simply disposing waste materials is not sustainable in the long term, as most raw materials are limited in supply. Waste recycling is yet to be fully exploited in Nigeria but some organizations are making it more attractive by creating awareness about its socio-economic benefits [6]. Resource recovery from wastes saves natural resources and energy. Discarded materials are local resources that have the potential to contribute to local revenue, employment creation, business expansion and local economic growth. Useful resources can be recovered from solid wastes through recycling, composting and incineration. It is a sustainability related activity which focuses on delaying the rate of consumption of natural resources.

\section{Recent Efforts at Resource Recovery by Lagos State}

The recent programs of waste management by Lagos State are not directly focused on recovery but management in general. The recovery aspect is implicit in all the programs. In 1997, the state government started ceding refuse collection in parts of the state to local operators to reduce the level of waste accumulation in different parts of the state [4]. In 2001, the state government co-opted the private sector fully into waste management through the Private Sector Participation (PSP) program by appointing private companies to invest in and participate in waste management. The Lagos State Waste Management Authority which had hitherto carried out collection and management of municipal solid waste was limited to collecting the wastes from transit points to the dump sites and management of the dump sites. This was meant to decentralize and deepen the penetration of waste collection throughout the state for improved efficiency. Resource recovery was not emphasized in the terms of reference.

The Lagos State Waste Management Authority Law of 2007 empowered the body to coordinate the activities of the PSPs for better delivery [7]. With the new law, waste collection became the full prerogative of the PSP operatives while LAWMA supervised them and managed the dump sites. With the dump sites now better managed, the informal sorting and removal of recyclable materials from the dump sites were organized for better flow and efficiency. Of note is the fact that sorting continued manually by scavengers but the collection points were better defined to ease access for the different vehicles that dump waste and collect reusable materials. The government did not fully address resource recovery until 2014 when a list of direct waste resource recovery guidelines were issued. They included; A plan to convert the Epe dump site to material recovery station; Increasing the treatment capacity of Odoguyan composting site to 500 tons (a private concern had started composting weeds from waterways in the area since 1995); Provision of sorting bins to those who are ready to sort and giving of rewards to encourage them; Invitation of private investors to do material recovery business with Lagos State Government; Establishment of LAWMA Recycling Bank, an initiative towards adoption of recycling as a veritable option to landfills. The bank shall serve as storehouse for paper, cans, glass and plastic waste to be situated in every estate within the Lagos metropolis. Some other programs within the same initiative are; Construction of a recycling plant at Olusosun; Waste to energy project at Ikosi for the purpose of generating electricity; Tyre straining facilities at Oshodi; Composting plant at Ikorodu; Material recovery facility at Mosimi.

In 2016, the government started the Cleaner Lagos Initiative (CLI) with the objective of turning waste to energy and creating jobs in Lagos. Visionscape Sanitation Solutions, a private waste management contractor was appointed to implement the plan. LAWMA was to be the regulatory body. Over time, Visionscape replaced the equipment of the PSPs with new and more technologically advanced machines and rendered the PSP's equipment redundant. Public outcry over the pile up of wastes around the state and the fate of the PSPs led to the jettisoning of the programme in 2019. The full potential of the measures mentioned are yet to be attained due to logistic and take-off issues.

\section{Methodology}

The research commenced with a review of newspaper publications and radio interviews granted by the state government officials on the subject of resource recovery from solid waste in the state. The different and similar positions held by the state from 2013 till date were identified and recorded. Effort was made to get the official gazettes of policy decisions by the state government on the subject matter. Some of the officials of the state ministries and 
government parastatals were also interviewed. Literature review on waste disposal improvement efforts and resource recovery by Lagos state was carried out within a wider coverage of best practices around the world. Findings from the investigation were organized before a field assessment was carried out. All the resource recovery programs that were identified from the initial investigations were verified online before proceeding to the different locations of the projects. The current levels of execution were recorded and itemized for easy reference.

A field survey was also carried out on the opinion of the residents of Lagos State on the measures being undertaken to improve resource recovery from solid waste in the state. A close ended questionnaire was administered to determine public opinion on incentives to sort waste into bins at source, the amounts charged for waste disposal by the government, the impact of the efforts on the environment, level of awareness of the efforts, general assessment of the efforts and level of enforcement of waste disposal guidelines. Lagos State has an estimated population of about 23 million residents. Using Slovin's formula for determination of sample size for large populations, a sample space of 400 residents was calculated. A total of 450 residents were requested to fill the simple questionnaire online. 411 participants responded to the request. The responses were tabulated and converted to a Likert scale table.

\section{Field Study Results}

Table 1. Situation reports on identified resource recovery programmes in Lagos State.

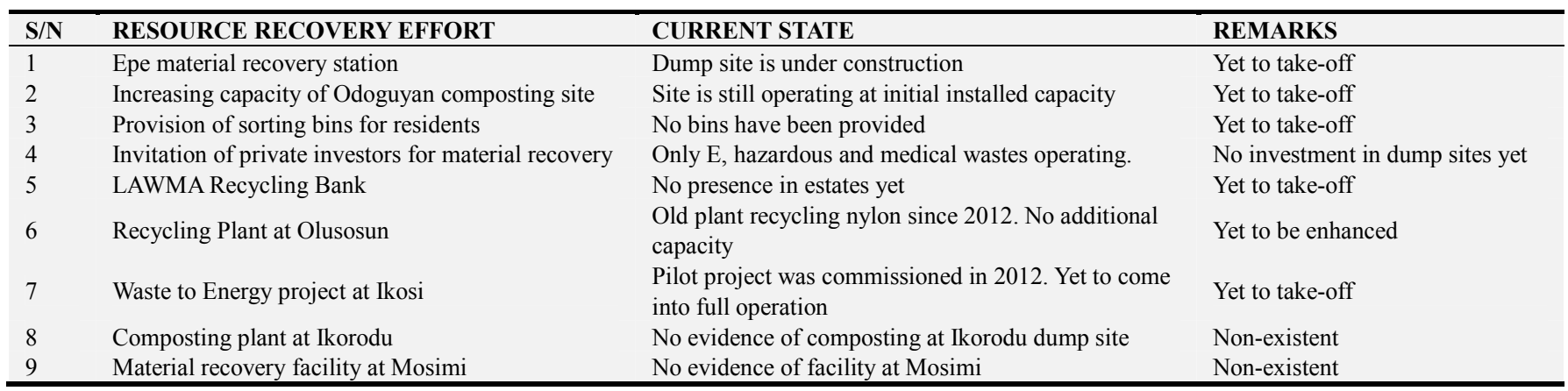

Source; Author (2020).

Table 2. Assessment of government efforts by residents of Lagos State.

\begin{tabular}{|c|c|c|c|c|c|c|}
\hline $\mathbf{S} / \mathbf{N}$ & GOVERNMENT EFFORT & VERY LOW & LOW & AVERAGE & HIGH & VERY HIGH \\
\hline 1 & Incentive to sort waste into bins at source. & 163 & 98 & 77 & 46 & 27 \\
\hline 2 & Amount charged for waste disposal & 9 & 119 & 128 & 137 & 18 \\
\hline 3 & Impact of efforts on the environment & 74 & 116 & 126 & 89 & 6 \\
\hline 4 & Level of awareness of the effort & 32 & 137 & 131 & 103 & 8 \\
\hline 5 & General assessment of the effort & 69 & 128 & 121 & 90 & 3 \\
\hline 6 & Level of enforcement of environmental laws & 70 & 145 & 101 & 89 & 6 \\
\hline
\end{tabular}

Source; Author (2020).

Table 3. Perception of government efforts by Lagos residents.

\begin{tabular}{llll}
\hline S/N & GOVERNMENT EFFORT & LIKERT SCORE & INFERENCE \\
\hline 1 & Incentive to sort waste into bins at source. & 1.88 & Very low \\
2 & Amount charged for waste disposal & 3.46 & Average \\
3 & Impact of efforts on the environment & 3.08 & Average \\
4 & Level of awareness of the effort & 3.24 & Average \\
5 & General assessment of the effort & 3.07 & Average \\
6 & Level of enforcement of environmental laws & 3.04 & Average \\
\hline
\end{tabular}

Source; Author (2020).

\section{Discussion}

To achieve the Sustainable Development Goals of the United Nations, the need to move modern societies towards circular economies (CE) is imperative [8]. With the promotion of circular systems around the world which are more regenerative the traditional linear economies are gradually being relegated. The idea of having materials labelled as waste, only to be discarded is against the principle of circularity. Resource recovery from agricultural wastes and e-wastes have very high levels of implementation in Lagos due to the high demand for their waste products. The e-wastes are usually packaged and exported. The medical wastes and harzardous chemicals are treated and either sold to factories who need such products or properly disposed of. The municipal solid wastes which are the subject of this research are the major materials in the landfills. The drive by 
the state government to promote resource recovery in the municipal solid waste system has been widely publicized in the media. Having itemized the major policy positions that the government proposed since 2014, the findings from the online and field assessment of the programs have revealed the extent of execution. The more technologically advanced economies have returned higher levels of resource recovery [9]. This implies that progress in technology and availability of financial resources are crucial to achieve appreciable levels of resource recovery. The technological and financial inputs are required in the collection, sorting and processing to make the waste accessible for consumption. Having so many of the programs at planning stage as evident in table 1 is an indication that the state is unable to generate resources to take-off points of the programs. There are also issues or prioritization of programs. It is more viable to embark on the upstream programs like domestic refuse sorting first before others that can be labelled as downstream. The downstream programs like recycling and composting depend on the upstream measures like sorting at source. Provision of sorting bins can be done at very little cost to the government. In well-organized communities, residents are encouraged to sort their wastes which are then collected separately. The entities that consume the sorted items can be advocated to invest in the collection process since they are getting the raw materials for their production. It must also be noted that production costs can sometimes be escalated when using recycled raw materials [10]. The use of recycled materials can also affect the quality of the final products. Use of recycled steel for steel coil production lowers the tensile strength considerably (Broadbent, 2016). The only way to ensure that the recycled wastes are consumed by the end users is to integrate the manufacturing facilities into the programs from the planning stages for their input. It is very important to create demand before the generation of recycled raw materials [11].

The outcomes of the investigation into the current states of the resource recovery programs are in three clusters. The first cluster comprises of the projects that have precursors but are yet to receive the added reinvestments to make them align better with the resource recovery intention of the government. The projects involved are the invitation of private investors into material recovery, capacity increase of Odoguyan composting plant and the construction of a modern recovery plant at the Olusosun dump site. Private investors have been involved in the aspects of resource recovery that have high demand for the recovered materials. The aspect of municipal waste which is the most challenging is not attracting enough patronage from the private sector. About $82 \%$ by mass of the municipal solid waste in Lagos are paper products and other biodegradable materials with a high potential for conversion into compost material [12]. It may not be attractive to private investors due to the high cost of conversion if compared with using regular raw materials. The position of the government is to invite the private sector to invest in resource recovery. Without enough incentives to attract the private investors into reusing the waste, it may be difficult to alter the current position. The state should synergize with the private sector on how to evolve incentives to make them adopt waste recycling as a raw material source. Mere invitation to invest may not suffice. The Olusosun dump site modern recovery plant had its beginning in 2012 when a pilot scheme for recovery was commissioned in the vicinity. The pilot project could only recycle nylon retrieved from the dump site. The full project was to have been commissioned at a later date. The pilot scheme has since remained redundant and the full project is yet to be implemented. Lack of continuity in government disposition towards solid waste management has been identified as a major factor militating against progress in this direction [13]. There have been two changes in governance since the pilot project. The subsequent administrations in the state never revisited the project though it has been mentioned in different media as an effort towards resource recovery. The details of the proposed plant have not been released. It is expected to produce $5 \mathrm{MW}$ of power in conjunction with another one proposed for the Epe dump site. Such plants are capital intensive and may be unable to compete with other power plants that use natural gas around Lagos. The composting operation that is ongoing at Odoguyan is a UN sponsored project that produces fertilizer from water hyacinth cleared from the lagoon and waterways. Plans and feasibility studies for a 35 hectare dump and composting facility next to the current plant were carried out and documented since 2009. Only the old plant is still operating till date. The new facility is yet to take off despite the fact that a private concern has been appointed to execute and manage the facility. Funding for the project has not been approved.

The next cluster of programs are those that have been earmarked for execution and locations have been allocated to them in some instances but are yet to take off. These include the Epe Materials Recovery Station, provision of sorting bins for residents and the LAWMA Recycling Bank. The Epe dump site is under reconstruction and expansion to relieve the Olusosun site which is about to be decommissioned in a few years. The materials recovery station is yet to be constructed. The recycling bank is a proposed transit station where waste sorting is carried out and packaged for recovery. The concept is laudable but yet to be allocated a site for its construction. Provision of sorting bins had been proposed by the state government since the year 2001. It still remains a recurrent proposal at every instance resource recovery is revisited in government proposals. The inability to initiate a concept and commence execution may be attributed to lack of commitment to the policies. The resources to execute these projects are not out of reach for the government. Land, funding and legislation are needed for take-off of the projects. Government is in a vantage position to acquire these resources. The private sector may not be attracted to such investments due to the lack of initial demand for the recovered materials.

The third cluster of resource recovery programs are those that have been publicized without any evidence of execution in the locations where they are supposed to be. The projects only exist in the media. These include the composting plant 
at Ikorodu and materials recovery plant at Mosimi. There is no evidence of the projects on ground. If these projects continue to receive attention in the mass media as part of the efforts of the state government to enhance resource recovery, the media owes the public a responsibility of detailed information on the statuses of the projects. These projects were being mentioned in radio programs as at 2014 .

The questionnaire survey to assess the perception of residents on the government efforts at resource recovery yielded average levels of perception for most of the indices prescribed to rate the assessment. The respondents returned a low score for the incentive to sort waste into bins at source. Many of the respondents are aware of the fact that sorting waste at source improves the levels of recovery. They are however unable to institute the practice on their own. The agency that collects the waste is yet to organize refuse collection along the lines of sorted items. The solid municipal wastes are collected and dumped together. Residents are required to pay monthly stipends to the state for refuse collection. The survey indicated that the amounts being charged in the different neighbourhoods are acceptable. Not too low and definitely not too high. The amounts charged may be subsidized by the state government if the cost of waste management exceeds the monthly turnover. The impact of efforts on the environment, the level of awareness of the efforts, the general assessment of the efforts and the level of enforcement of environmental laws returned average scores on the Likert five-point scale. Having such scores with very little on ground is an indication of the high media drive on the programs. The Cleaner Lagos Initiative (CLI) was highly publicized as an instant panacea for all the waste management problems of the state. When the program started and the coverage was too low in comparison with the level of waste generation, the residents complained and demanded for the return of the PSPs. Government had to backtrack after just one year and return to the previous arrangement. If the government and the people had resolved that improvement is needed on an issue, whatever measures that get implemented as a solution should be well researched before application. The state government claimed they had hired specialists and consulted within the ministries before coming out with the position. The measures were either deficient or wrongly implemented. The resource recovery threshold of the program was never attained. Resource recovery is seen as an integral part of waste management within the state. The bottom line is that residents are aware of the government efforts but are oblivious of the fact that there's a very low level of execution. Resource recovery can be initiated by the government but the ultimate execution lies with the participation of the private sector for better efficiency and continuity. Resource recovery must also be sustainable, creating wealth for those concerned to make it viable [14]. Public awareness and participation are expedient for sustainable resource recovery [15]. The efforts must also be properly integrated into a circular economy for continuity [16]. Resource recovery from solid waste cannot be achieved to any reasonable extent without a total orientation of the larger economic principles of the state and country. It cannot be practiced in isolation of the entire polity. As the state strives for economic growth within an overwhelming rate of urbanization, it is generally expected that solid waste generation would increase. The idea of economic growth and rapid urbanization must be decoupled from higher levels of waste generation and consumption of primary raw materials $[17,18]$. Without restructuring the whole polity of the state and seeking for cooperation with the federal entity, to embrace the principles of circular economy, the achievement of solid waste resource recovery at appreciable levels is bound to be very challenging.

\section{Conclusion}

The Lagos state government has made several efforts to initiate solid waste resource recovery since 2007. Most of the initiatives have evolved into policy positions with very low levels of implementation. While the populace is aware of the noble intentions of the government, they have shown a high level of ignorance of the projects that are supposed to enhance the policy positions. The residents are also willing to participate if the programs are well packaged to be inclusive. The private sector which should be the driving force behind the efforts have not shown enough interest in municipal solid waste resource recovery. The dump sites are still growing with proposals for more dump sites in the making. The approach of the state government to the objective is entrenched within the ambits of the more linear economy that is in operation in the country. A holistic approach that starts with adjustments of the state and federal economies towards circularization will definitely enhance delivery of the objective. The inclusiveness that is also ideal in realizing the objective is subsumed in the global adjustment being proposed.

\section{References}

[1] Ajaero, C. K., \& Onokala, P. C. (2013). The effects of ruralurban migration on rural communities of southeastern Nigeria. International Journal of Population Research, 2013.

[2] Adedayo, A. F., \& Malik, N. A. (2015). Factors influencing the growth of slums in Lagos metropolis, Nigeria. Ethiopian Journal of Environmental Studies and Management, 8 (2), 113-119.

[3] Anestina, A. I., Adetola, A., \& Odafe, I. B. (2014). Performance assessment of solid waste management following private partnership operations in Lagos State, Nigeria. Journal of Waste Management, 2014.

[4] Oyelola, O., Ajiboshin, I., \& Okewole, J. (2017). Effective solid waste management in the circular economy: The case study of Lagos state, Nigeria. Procedia Environmental Science, Engineering and Management, 4 (3), 143-148.

[5] Adewole, A. T. (2009). Waste management towards sustainable development in Nigeria: A case study of Lagos state. International NGO Journal, 4 (4), 173-179. 
[6] Nzeadibe, T. C. (2009). Solid waste reforms and informal recycling in Enugu urban area, Nigeria. Habitat international, 33 (1), 93-99.

[7] Nwokike, L. I. (2020). Lagos Waste Management Authority law 2007 and National Environmental Standards and Regulations Enforcement Agency (establishment) act 2007: A comparative appraisal. African Journal of Law and Human Rights, 4 (2).

[8] Velenturf, A. P., \& Purnell, P. (2017). Resource recovery from waste: Restoring the balance between resource scarcity and waste overload. Sustainability, 9 (9), 1603.

[9] Zaman, A. U. (2016). A comprehensive study of the environmental and economic benefits of resource recovery from global waste management systems. Journal of cleaner production, 124, 41-50.

[10] Lee, J. C., Edil, T. B., Tinjum, J. M., \& Benson, C. H. (2010). Quantitative assessment of environmental and economic benefits of recycled materials in highway construction. Transportation research record, 2158 (1), 138-142.

[11] Hogg, D., Durrant, C., Thomson, A., \& Sherrington, C. (2018) Demand Recycled: Policy options for increasing the demand for post-consumer recycled materials. Report for Resource Association and WWF UK.

[12] Adebayo, O. O., \& Ojetayo, T. A. (2001). Beneficial uses of
Lagos state municipal solid waste. Mechanical Engineering Department, University of Lagos, Nigeria, 22-27.

[13] Kofoworola, O. F. (2007). Recovery and recycling practices in municipal solid waste management in Lagos, Nigeria. Waste management, 27 (9), 1139-1143.

[14] Lehmann, S. (2010). Resource recovery and materials flow in the city: Zero waste and sustainable consumption as paradigms in urban development. Sustainable Dev. L. \& Poly, $11,28$.

[15] Shekdar, A. V. (2009). Sustainable solid waste management: an integrated approach for Asian countries. Waste management, 29 (4), 1438-1448.

[16] Gregson, N., Crang, M., Fuller, S., \& Holmes, H. (2015). Interrogating the circular economy: the moral economy of resource recovery in the EU. Economy and society, 44 (2), 218-243.

[17] Singh, J., \& Ordoñez, I. (2016). Resource recovery from postconsumer waste: important lessons for the upcoming circular economy. Journal of Cleaner Production, 134, 342-353.

[18] Akinbola B. R. (2009). Waste Management and International Environmental Law: Emerging Trends and Implication in Nigeria. International Journal of Environmental Issues Volume 6, Nos 1\&2. Development Universal Consortium. 